\title{
CONSIDERATIONS ON THE USE OF DIGITAL TOOLS FOR DOCUMENTING ANCIENT WALL GRAFFITI
}

\author{
R. Valente ${ }^{1}$, L. Barazzetti ${ }^{1}$, M. Previtali ${ }^{1}$, F. Roncoroni ${ }^{2}$ \\ ${ }^{1}$ Politecnico di Milano, ABC Department, piazza Leonardo da Vinci, 32, 20133 Milano \\ ${ }^{2}$ Polo territoriale di Lecco, via Previati $1 / \mathrm{c}$, Lecco \\ (riccardo.valente, luigi.barazzetti, mattia.previtali, fabio.roncoroni@polimi.it)
}

\section{Commission II}

KEY WORDS: Digital Photogrammetry, RTI, Wall Graffiti, Heritage Documentation

\begin{abstract}
:
Ancient graffiti are a valuable and constant historical evidence through the human history, regardless from the geographic area or historical period. They can be found on different kinds of surfaces and in different contexts, such as religious building or civic structures, in public or private environments. Their study and comprehension need to be grounded on good and complete documentation techniques. The application of accurate recording methods is even more important for ancient graffiti, for a series of reasons. First of all, their perception is often less immediate than other historical or artistic evidence, and directly depends on external aspects, such as the lighting conditions, and personal skills. Moreover, their interpretation is often challenging also for expert scholars, so as to require both the most objective reproduction possible and the personal interpretation of the scholar. As a case study, several late medieval graffiti scratched on frescos have been documented with digital methods. Results will be presented and discussed. This paper will mainly focus on graffiti scratched on frescos or plaster, and not on petroglyphs, i.e. marks and drawings on rock surfaces.
\end{abstract}

\section{INTRODUCTION}

Wall graffiti are a relevant and constant historical evidence which belongs to almost all of those human groups over the centuries who have writing skills; not considering for this work prehistoric and proto-historic petroglyphs, in Europe the presence of graffiti is nearly seamless from the Roman period to our days (Miglio and Tedeschi, 2012, Forster et al., 2012, Champion, 2018). When documenting ancient wall graffiti, two main goals need to be addressed. The first one is to have the most exact and objective reproduction possible of the evidence. The second goal is to obtain an output which is the result of the human interpretations of scholars. These two steps are crucial, since the same graffito could be read and interpreted in different ways: a correct documentation should assure both of them.

These requirements result in a different approach to documentation than what usually applied to other Cultural Heritage objects, where an objective approach as much complete as possible is generally enough. For graffiti documentation, as well as for rock art, this first step will be necessarily integrated by a graphic representation (drawing) of what has been interpreted. The personal intervention during the realization of this second output is the reason why just a single interpreted drawing could not be sufficient, according to the different possible proposed readings. Unlike other historical evidence, several constraints often make graffiti documentation a difficult task compared to other cases. Main issues are:

- poor visibility due to unfavourable lighting conditions: dark rooms or wrong light set prevent almost completely to individuate and observe graffiti;

- poor visibility due to bad surface conditions: the presence of physical lacks or other kinds of damage affecting the surface often result in a low quality documentation;
- small size of inscriptions: size of a large number of graffiti is millimetric;

- presence of different layers of writing: multiple and overlapping writing phases (palimpsest) avoid a one-by-one approach;

Traditional documentation techniques for wall graffiti basically come from archaeological methods used to record rock art (Anati, 1974, Sanz, 2014, Marretta, 2014)and epigraphs (Di Stefano Manzella, 1987). One of the most used techniques is still today contact tracing, obtained by tracing the profiles of the marks on transparent sheets laid out on the surface. It is a simple and efficient method that allows not only to reproduce the morphology of incisions but also the marks' overlapping, an important detail to reconstruct chronology: the so-called "stroke selection" is a crucial operation led by archaeologists, palaeographers and epigraphists who select the lines belonging to a graffito and expunge those ones which are not relevant or belong to other inscriptions. This technique has been used for decades to document and analyse petroglyphs all over the world and was successfully tested also on wall graffiti (Bassi and Bellandi, 2009). However, a wider application is often constrained by conservation needs when applied to frescoed or decorated surfaces, because frescos are fragile and contact should be avoided in any possible way. Photographs have been used as well to document graffiti, usually with the help of raking light. Despite their effectiveness, they are often affected by some important drawbacks when documenting graffiti: raking light introduces a large number of uncontrolled shadows, especially with graffiti extended in length. This point means that many images are not useful to eliminate uncertainties and doubts about the reading, and the final results strongly depends on the photographer's skills. Moreover, it is very important not to lose the connection with the surrounding graffiti of the same wall; the only way to fix this issue with traditional images 
The International Archives of the Photogrammetry, Remote Sensing and Spatial Information Sciences, Volume XLII-2/W9, 2019 8th Intl. Workshop 3D-ARCH “3D Virtual Reconstruction and Visualization of Complex Architectures", 6-8 February 2019, Bergamo, Italy
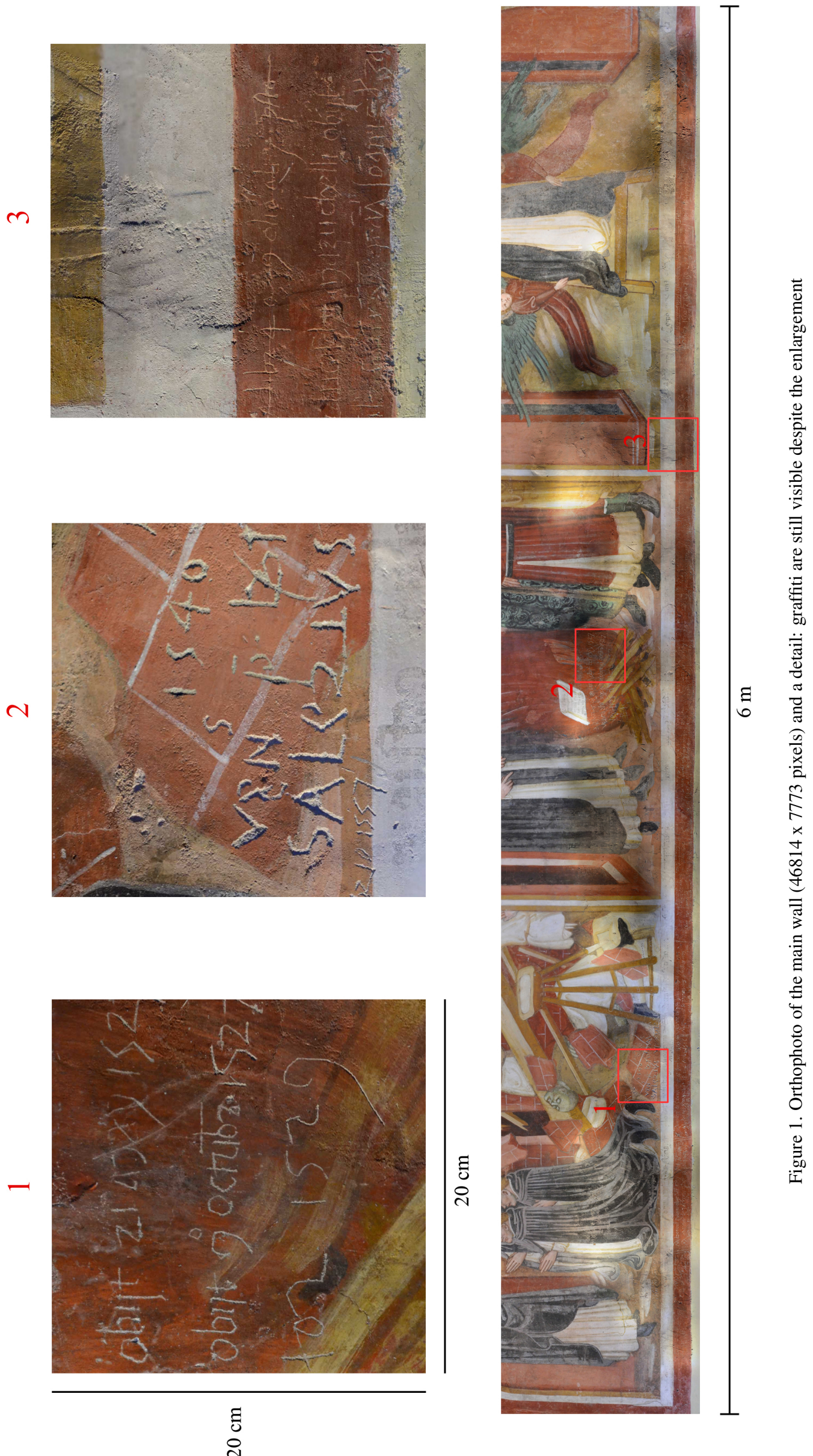

This contribution has been peer-reviewed. 
is to take several images with different enlargement factors, although a wide field of view causes a loss in details resolution. In the last decades, digital recording techniques introduced deep changes in documentation practice of Cultural Heritage and graffiti as well. Reflectance Transformation Imaging (RTI) is a computational photographic method and one of the most experimented recording techniques: it enhances small details and changes in objects' surfaces using their reflectance properties, and it also allows to change the lighting conditions in an adaptive way(Malzbender et al., 2001, Earl et al., 2010, Palma et al., 2010). All of these characteristics are relevant features when documenting graffiti: it has been successfully tested to document both wall graffiti and rock art (Mudge et al., 2006, Mudge et al., 2012, Cosentino et al., 2015, Díaz-Guardamino et al., 2015, Kotoula et al., 2018, Sammons, 2018).

\section{CASE STUDY AND METHODOLOGY}

Laser scanning is an established surveying technology that revolutionized the entire approach to survey(Vosselman and Maas, 2010). It was also tested on wall graffiti and rock art; used instruments are triangulation-based laser scanners or structured light lasers (Balzani et al., 2004, Alexander et al., 2015). This approach allows to obtain a very detailed digital reconstruction of the wall surface and a submillimetric precision, although it requires more skills and greater funds for instruments; triangulation laser scanners are preferable to time-of-flight or phase-shifting instruments in order to achieve a greater accuracy and precision. Digital Photogrammetry is another digital surveying technique that was completely changed by digital revolution, widening its use to a broader public(Mikhail et al., 2001, Hartley and Zisserman, 2004, Luhmann et al., 2006, Kraus, 2008). Structure from Motion techniques along with computer vision algorithms allowed to apply terrestrial photogrammetry to a wider number of objects, included rock art (Carrero-Pazos et al., 2018) and epigraphy (Carrero-Pazos and Espinosa-Espinosa, 2018). Despite its user-friendly approach and the inclusion of this method together with other techniques in the official guidelines for graffiti recording written by Historic England, digital photogrammetry appears to be preferably used to record the wider context where graffiti lay (e.g. the standing structure, or the entire wall) rather than focusing on the single graffiti (Historic England, 2015). Its use can be instead successfully applied to document single graffiti in order to obtain rectified images, from which detailed digital drawings can be realized as substitution of traditional contact tracings (Valente and Oreni, 2017).

\subsection{Case Study presentation}

Selected case study is a group of ancient wall graffiti located in the church of S. Filastrio in Tavernole sul Mella, (Brescia, Italy). The building dates back to Middle Ages, and it is one of the most important artistic evidence of the area (Fig. 2). Graffiti are located into a small side chapel: inner walls are completely covered with a fresco cycle of s. Domenico (Spada, 1975, D'Attoma, 2018). Their chronology is included between $15^{\text {th }}$ and $19^{\text {th }}$ century. Their recording is part of a wider project of analysis and contextualization of graffiti in Tavernole. Only few historical images, acquired in the 1980 s, are available, so a new documentation campaign was mandatory.

\subsection{Used Methodology}

In order to document ancient wall graffiti by a fully contactless method, digital photogrammetry was used. An entry-level and re-
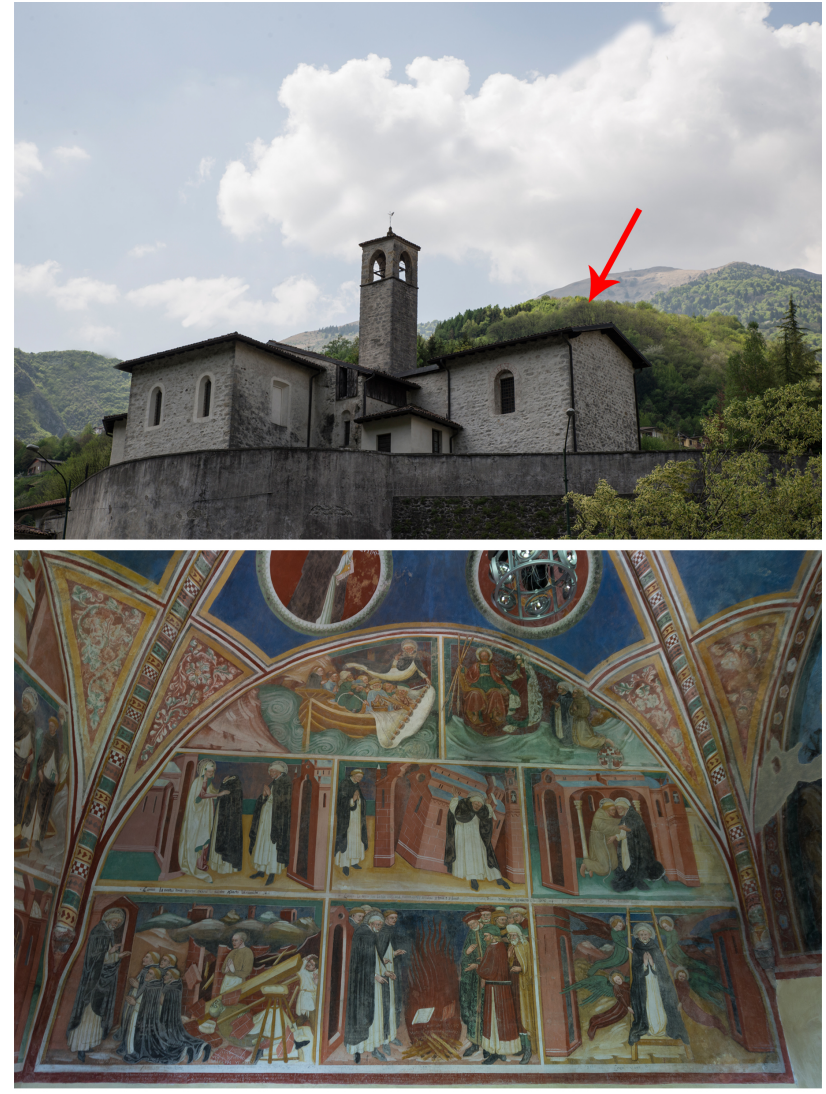

Figure 2. Chirch of S. Filastrio (above) and inside view of frescoed chapel (below)

flex camera (Nikon D3100, sensor 23,1 mm x 15,4 mm, equipped with $18-55 \mathrm{~mm}$ lens) was chosen to test results that can be obtained also with a very basic equipment. A wall six metres long was selected because of the high number of graffiti all over the surface and for their differences in size and visibility (Fig.1).

The camera distance was set to $1 \mathrm{~m}$ from the wall. An overall number of 194 images were processed with PhotoScan Professional 1.4.0 in order to align them and to reconstruct the digital surface of the wall (Agisoft PhotoScan). Images were taken paying attention to the needed superimposition along a line parallel to the wall, obtaining a sequence of images: the ground sample distance was $0.09 \mathrm{~mm}$ (Fig.3). One of the main aims was to keep a high detail and resolution all of the final image, despite the relevant length of wall surface.

A second test was carried out with a different equipment (Nikon

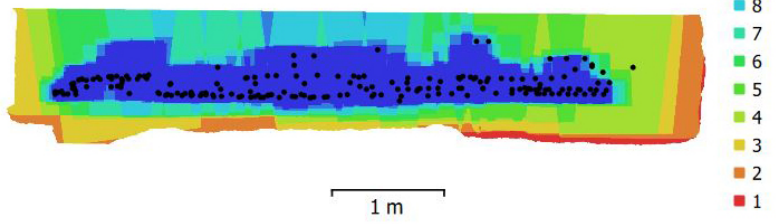

Figure 3. Main wall: overlapping cameras as displayed in the PhotoScan report 
D90, sensor 23,6 x 15,8 mm, equipped with $90 \mathrm{~mm}$ macro lens). This gear allowed to acquire images for digital photogrammetry very close to the wall surface and with a relevant enlargement factor. A small portion of another wall with two graffiti was selected, for an overall extension of $70 \mathrm{~cm}^{2}$. A series of 44 images were acquired from very close distance $(18 \mathrm{~cm})$ and processed and georeferenced as previously presented. The ground sample distance was $0.01 \mathrm{~mm}$ (Fig.4). Both photogrammetric blocks were acquired using a tripod: the use of this gear proved to be necessary due to the scarce light intensity, and it avoided blurrings even when using the macro lens; it also helped to keep unvaried the distance from the wall surface.
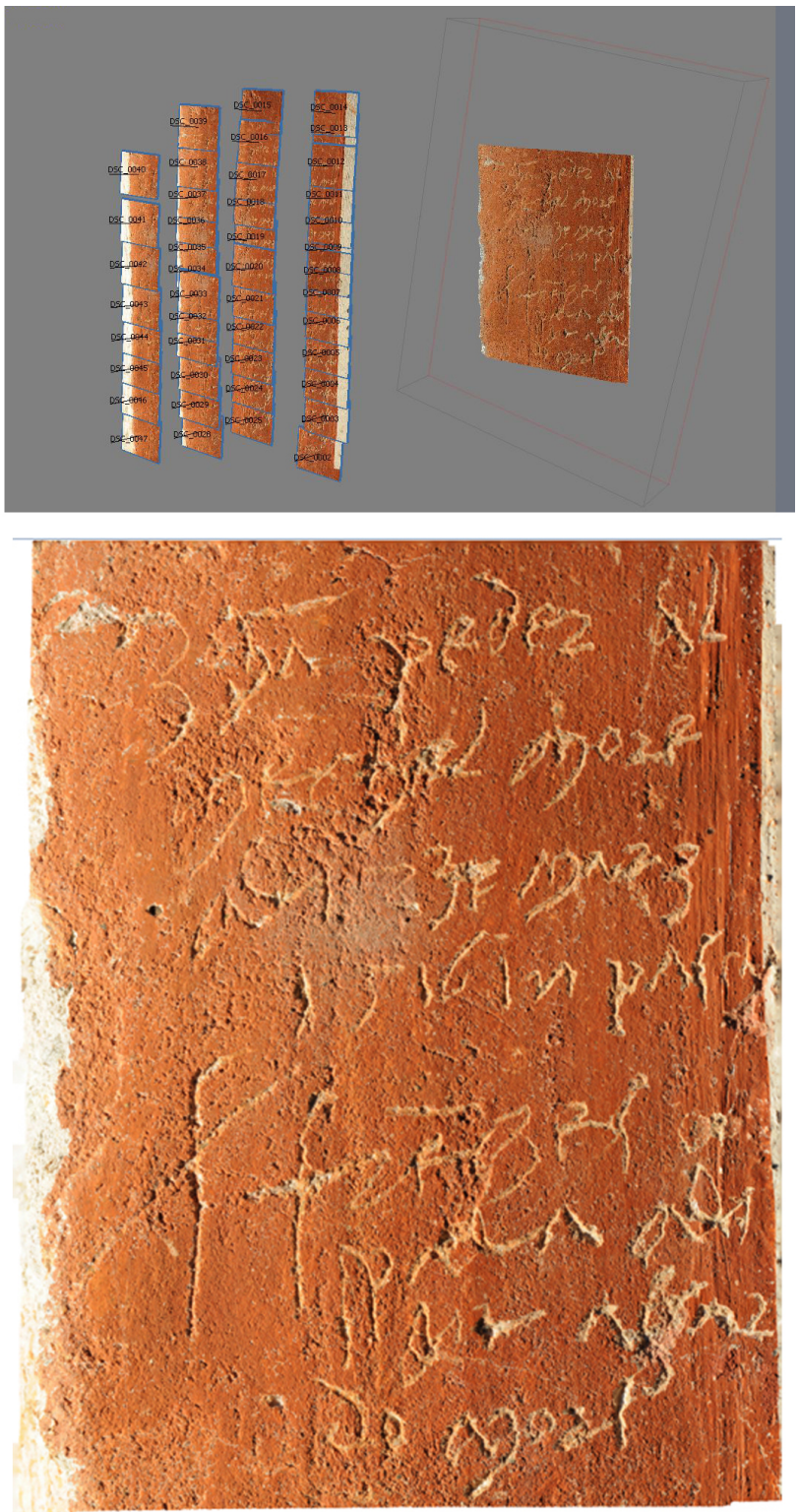

Figure 4. Macro image set (above) and resulting orthophoto (below)

Total station measurements were performed to establish a local reference system, using a Leica 1203 total station instrument. Since all the visible surfaces were covered by frescos, the use of coded targets was not possible; to overcome this issue, a series of points corresponding to intersections of geometric frescoed decorations was measured; an overall number of 26 ground control points (GCPs) was measured. One of the main issues relating the use of control points measured with a total station is the precision of such measurements. The direct measurement (without multiple intersection) allows one to obtain a precision of about $2 \mathrm{~mm}$. This is worse than the expected precision of photogrammetric projects, especially those with a very short camera object distance (Fig. 5). For this reason, it was decided to use ground control points as constraint to estimate a seven parameter trasfromation ( 3 translations, 3 rotation, 1 scale factor) instead of including control points as pseudo-observation. This does not mofify the overall shape of the photogrammetric project and it results in an averall georeferencing error.

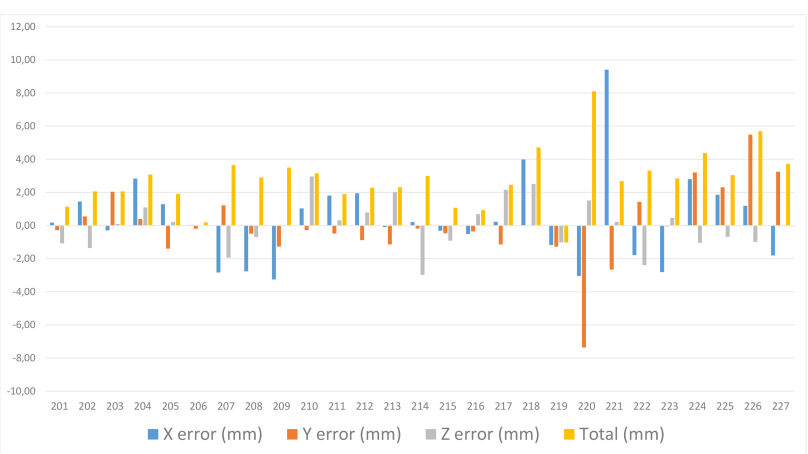

Figure 5. Ground Control Point errors of long wall photogrammetric set

In order to improve the quality of graffiti documentation, a RTI set was also prepared. In this case, few graffiti which appeared to be poorly visible and readable were selected. Two $20 \mathrm{~mm}$ black glossy spheres were positioned close to the selected graffiti; each sphere was placed on top of a metal rod, in order to avoid also in this case any possible contact with the decorated surface. A series of images, from a minimum of 12 up to 25 , was shot from a fixed position with the only variation of lighting direction, according to the RTI image capturing procedure and successively processed. Since with graffiti, unlike 360 degrees features, the key point is to enhance the depth of strokes, a circular lighting scheme with an inclination angle lower than 15 degrees was preferred to a more classical hemispherical set, while a fixed distance of light from the subject was kept: this change in the lighting scheme caused a reduction of the number of images normally taken.. Images were processed with RTIBuilder 2.0.2 software, distributed as open source by CHI - Cultural Heritage Imaging (RTI Builder) Processing phase is user-friendly and required only few minutes for each project.

After this step, different visualization of graffiti according to different light directions were available, as if the operator was on the field moving the light source; moreover the several rendering modes which can be applied (for instance, Specular Enhancement or Normals Visualization) increase the opportunities to enhance and make visible details hard to be perceived in natural conditions. RTI Viewer 1.1 software was used to check the outputs and modify rendering modes (RTI Viewer).

\section{RESULTS AND DISCUSSION}

Orthophotos were the main output obtained from the photogrammetric projects. In the first case, the orthophoto reproduces the entire 6 metres long wall surface: with a pixel value of $0,6 \mathrm{~mm}$ graffiti are very visibile in every portion of the surface and can 

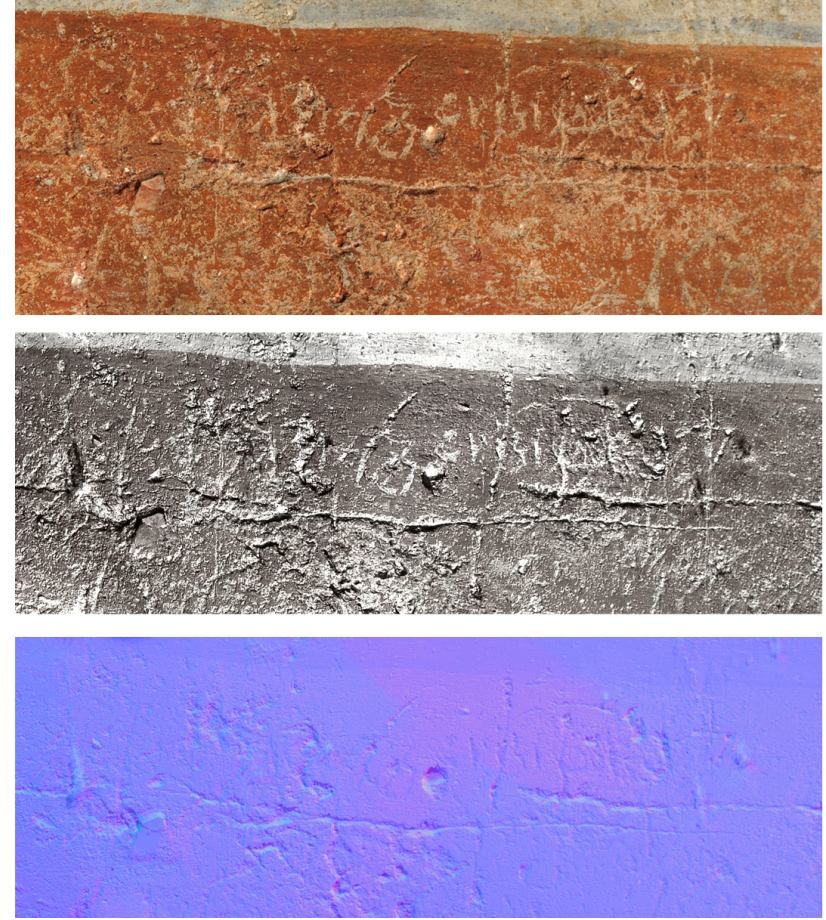

Figure 6. RTI outputs: Default mode (above); Specular Enhancement (middle); Normals Visualization (below)

be easily read. Since the spatial continuity of the wall was preserved, it was possible to detect not only single graffiti or groups of them, as with single shots, but to observe wider parts of the surface; this helped to consider the single features as part of a larger spatial framework, improving the "stroke selection". The "multi-scale" approach made possible by such large and detailed images, that allow a great range of magnification, is a positive improvement for what concerns the analysis of graffiti, being a feasible and effective support to on-site inspection, as well as an excellent documentation. In regard to the presented case study, the large sizes of documented area did not prevent to obtain the demanded resolution.

The second orthophoto obtained from the macro image set resulted to have a pixel value of $0,02 \mathrm{~mm}$, which is good enough to display small details, such as the stroke depth and some secondary marks. Most of these details are hard to catch by naked eye and offer additional information about the writing gestures. On this output, the dimensions of single strokes were easily measurable, even when one deals with submillimetric sizes (Fig.7). This feature can help to make hypothesis about tools used to scratch the inscriptions and to make measurement comparisons in order to identify similarities. Despite the small size, the stroke depth is visible also on the three-dimensional mesh.

Tests proved that digital photogrammetry is an efficient and feasible method to document ancient wall graffiti. The use of orthopohotos to document ancient graffiti on sub-planar surfaces represents a great improvement compared to traditional methods. It allows to obtain undistorted images which can be used as affordable metric reference to perform dimensional analysis of the elements and enhance the visibility of thin strokes. The digital image mosaic helps to minimize the drawbacks of raking light, which still remains the preferable lighting condition to make graffiti readable (Fig.8). Orthophotos help the process of reading and interpretation of graffiti, which sometimes are even more visi- ble than what can be experienced on the site, allowing enlargements which would be difficult to obtain in other ways. Moreover, unlike with single traditional or digital images, the orthomosaic allows to manage different levels of enlargement, varying scale without losing the surrounding context, a crucial aspect for graffiti identification and comprehension.

The methodology can be used for wall graffiti of any period, and it is particularly effective for graffiti scratched on the surface. The possibility of recording and measuring without any physical contact is extremely important for graffiti realized on frescoed surfaces, increasing the possibility of documenting, studying and preserving this important historical evidence. This method is particularly effective when dealing with subplanar surfaces, since orthophotos can be directly measured without any additional operation; in case of subcylindrical surfaces, such as the interior part of frescoed apses or columns, other operations like digital unwrapping need to be performed. With irregular surfaces, such as natural rocks with petroglyphs, other strategies need to be considered.

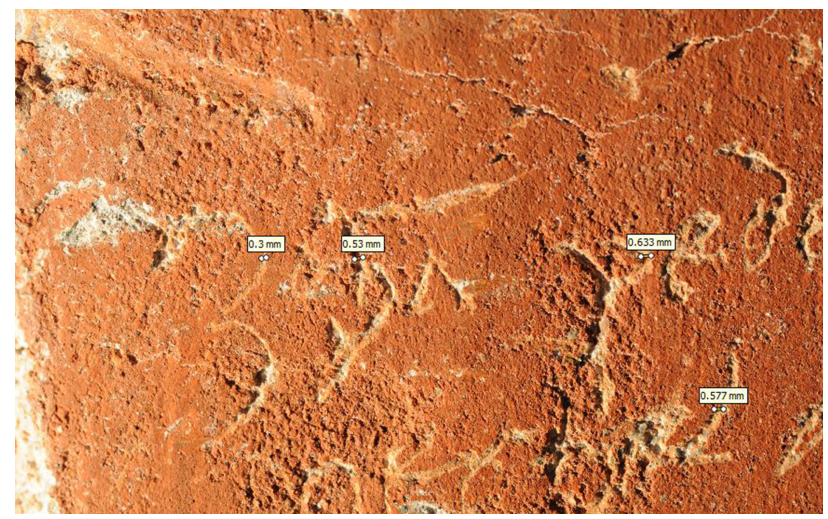

Figure 7. Measurements of graffiti lines performed on single cameras in PhotoScan

For what concerns RTI, text confirmed that is an important imaging method, particularly useful for the documentation of inscriptions and graffiti, although the real improvement of reading condition should be carefully evaluated. For instance, the use of RTI in the presented case did not help to reach an interpretation of graffiti which was applied to, probably because of the very poorly preserved conditions of the wall surface. Ambient light was not completely shaded due to logistic constraints, and this aspect could have decreased the effectiveness of the method. Even when not crucial for graffiti reading, RTI proved to be a method that can be successfully used for communication or educational purposes. The possibility to change the light direction and to observe the changes in graffiti perception increase the remote interactivity, an aspect that could be useful to improve a digital fruition with a special consideration to preservation needs.

\section{CONCLUSIONS}

The paper presented the use of digital tools to document ancient graffiti. The high level of detail required for the documentation makes image acquisition more complex than traditional photogrammetric project. Despite the additional efforts required to set the image acquisition, final results are a relevant improvement of usual photographic documentation of graffiti, which is 

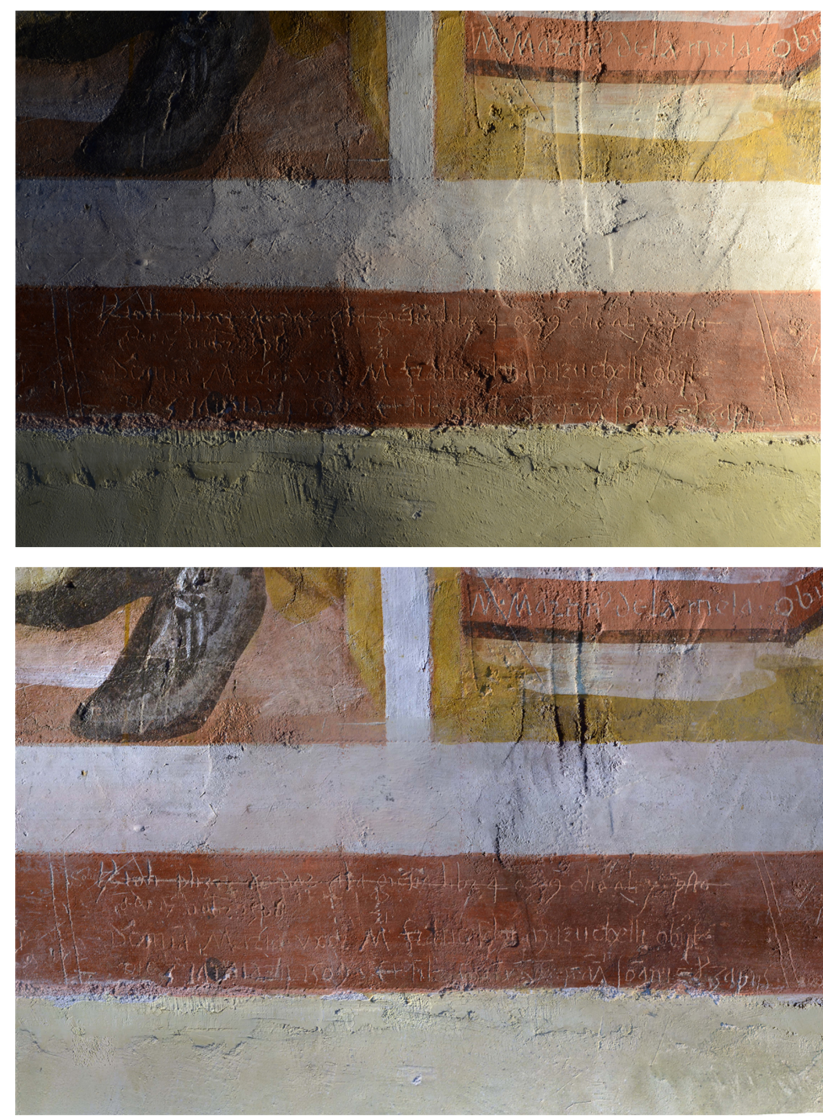

Figure 8. Improved readability: traditional light setting (left) vs. orthophoto (right)

frequently affected by several issues. No special instruments are needed, except for total station, and good results can be also achieved with an entry-level equipment. RTI software is available for free on the web and it allows to integrate the overall documentation, keeping a low-cost approach. The use of macro lenses proved to be a suitable solution to reach a resolution which goes far beyond human eye perception. Although the documentation of large wall portions from such a close distance could be very challenging and demanding for what concerns computational resources, their use can be considered when an extra detail is needed.

\section{REFERENCES}

Agisoft PhotoScan, http://www.agisoft.com/.

Alexander, C., Pinz, A. and Reinbacher, C., 2015. Multi-scale 3d rock-art recording. Digital Applications in Archaeology and Cultural Heritage 2(2-3), pp. 181-195.

Anati, E., 1974. Metodi di rilevamento e di analisi dell'arte rupestre. Capo di Ponte.

Balzani, M., Callieri, M., Fabbri, M., Fasano, A., Montani, C., Pingi, P., Santopuoli, N., Scopigno, R., Uccelli, F. and Varone, A., 2004. Digital representation and multimodal presentation of archeological graffiti at pompei. In: Y. Chrysanthou, K. Cain and F. Silberman, N. \& Niccolucci (eds), VAST 2004: The 5th International Symposium on Virtual Reality, Archaeology and Cultural Heritage, The Eurographics Association, pp. 93-103.
Bassi, S. and Bellandi, G., 2009. L'applicazione delle metodologie di rilievo dell'arte rupestre della valcamonica nella documentazione di graffiti su affresco. Bulletin d'études préhistoriques et archéologiques alpines (XX), pp. 257-264.

Carrero-Pazos, M. and Espinosa-Espinosa, D., 2018. Tailoring 3d modelling techniques for epigraphic texts restitution. case studies in deteriorated roman inscriptions. Digital Applications in Archaeology and Cultural Heritage 10, pp. e00079.

Carrero-Pazos, M., Vilas-Estévez, B. and Vázquez-Martínez, A., 2018. Digital imaging techniques for recording and analysing prehistoric rock art panels in galicia (NW iberia). Digital Applications in Archaeology and Cultural Heritage 8, pp. 35-45.

Champion, M., 2018. Medieval graffiti inscriptions. In: C. M. Gerrard and A. Gutiérrez (eds), The Oxford Handbook of Later Medieval Archaeology in Britain, Oxford Univ Pr, Oxford, pp. 626-640.

Cosentino, A., Stout, S. and Scandurra, C., 2015. Innovative imaging techniques for examination and documentation of mural paintings and historical graffiti in the catacombs of san giovanni, syracuse. International Journal of Conservation Science 6(1), pp. 23-34.

D'Attoma, B., 2018. S. filastrio a tavernole. In: F. Ghigini (ed.), Gli Antichi Originari. Cimmo e Tavernole. La storia, la comunità, l'arte, il paesaggio, Vol. I, Gardone Val Trompia, pp. 127-163.

Di Stefano Manzella, I., 1987. Mestiere di epigrafista. Guida alla schedatura del materiale epigrafico lapideo. Roma.

Díaz-Guardamino, M., Sanjuán, L. G., Wheatley, D. and Zamora, V. R., 2015. RTI and the study of engraved rock art: A reexamination of the iberian south-western stelae of setefilla and almadén de la plata 2 (seville, spain). Digital Applications in Archaeology and Cultural Heritage 2(2-3), pp. 41-54.

Earl, G., Martinez, K. and Malzbender, T., 2010. Archaeological applications of polynomial texture mapping: analysis, conservation and representation. Journal of Archaeological Science 37(8), pp. 2040-2050.

Forster, A. M., Vettese-Forster, S. and Borland, J., 2012. Evaluating the cultural significance of historic graffiti. Structural Survey 30(1), pp. 43-64.

Hartley, R. I. and Zisserman, A., 2004. Multiple View Geometry in Computer Vision. Cambridge University Press, Cambridge.

Historic England, 2015. Recording historic graffiti: Advice and guidance. techreport, Historic England.

Kotoula, E., Robinson, D. and Bedford, C., 2018. Interactive relighting, digital image enhancement and inclusive diagrammatic representations for the analysis of rock art superimposition: The main pleito cave (CA, USA). Journal of Archaeological Science 93, pp. 26-41.

Kraus, K., 2008. Photogrammetry: Geometry from Images and Laser Scans. Walter de Gruyter.

Luhmann, T., Robson, S., Kyle, S. and Harley, I., 2006. Close Range Photogrammetry: Principles, Techniques And Applications. John Wiley \& Sons.

Malzbender, T., Gelb, D. and Wolters, H., 2001. Polynomial texture maps. In: Proceedings of the 28th annual conference on Computer graphics and interactive techniques - SIGGRAPH '01, ACM Press, pp. 519-528.

Marretta, A., 2014. Tecniche di incisione e metodi di documentazione dell'arte rupestre in area centro-alpina: una panoramica aggiornata. Notiziario dell'Istituto Archeologico Valtellinese (11), pp. 7-20. 
Miglio, L. and Tedeschi, C., 2012. Per lo studio dei graffiti medievali. caratteri, categorie, esempi. In: P. Fioretti (ed.), Storie di cultura scritta. Studi per Francesco Magistrale, Spoleto, pp. 605-628.

Mikhail, E. M., Bethel, J. and McGlone, J. C., 2001. Introduction to Modern Photogrammetry. John Wiley \& Sons.

Mudge, M., Malzbender, T., Schroer, C. and Lum, M., 2006. New reflection transformation imaging methods for rock art and multiple-viewpoint display. In: Proceedings of the 7th International Conference on Virtual Reality, Archaeology and Intelligent Cultural Heritage, VAST'06, Eurographics Association, Aire-laVille, Switzerland, Switzerland, pp. 195-202.

Mudge, M., Schroer, C., Noble, T., Matthews, N., Rusinkiewicz, S. and Toler-Franklin, C., 2012. Robust and scientifically reliable rock art documentation from digital photographs. In: A Companion to Rock Art, John Wiley \& Sons, Ltd, pp. 644-659.

Palma, G., Corsini, M., Cignoni, P., Scopigno, R. and Mudge, M., 2010. Dynamic shading enhancement for reflectance transformation imaging. Journal on Computing and Cultural Heritage 3(2), pp. 1-20.

RTI Builder, http://culturalheritageimaging.org/ What_We_Offer/Downloads/Process/index.html; last access: December 2018..

RTI Viewer, http://culturalheritageimaging.org/ What_We_Offer/Downloads/View/index.html; last access: December 2018.

Sammons, J. F. D., 2018. Application of reflectance transformation imaging (rti) to the study of ancient graffiti from herculaneum, italy. Journal of Archaeological Science: Reports 17, pp. 184-194.

Sanz, I. D., 2014. Rock art recording methods: From traditional to digital. In: C. Smith (ed.), Encyclopedia of Global Archaeology, Springer New York, New York, NY, pp. 6351-6357.

Spada, E., 1975. Tavernole sul mella e la sua centrale magistratura. In: Tavernole ieri e oggi, Brescia.

Valente, R. and Oreni, D., 2017. Survey and drawings for the study and enhancement of ancient wall graffiti: the case of the baptistery of castiglione olona. DISEGNARECON 10(19), pp. 7.1-7.10.

Vosselman, G. and Maas, H. G., 2010. Airborne and Terrestrial Laser Scanning. Whittles Publishing, Caithness. 